99.99 per cent (information can be given as to where they can be obtrined); (2) metals of high purity, not generally available, which have been produced for the Department and can be supplied for research purposes; (3) metals not yet available in a pure state but which are being produced for the Depart. ment; (4) metals which do not appear to be of sufficient interest to justify action at the present time. All inquiries regarding this work, including information regarding metals in group 1 and the conditions under which metals in group 2 can be made available to research workers, should be addressed to the secretary of the D.S.I.R. Pure Metals Committee, Metallurgy Division, National Physical Laboratory, Teddington, Middlesex.

\section{Natural History on Stamps}

As article in a recent issue of the Australian Museum Magazine (10, No. 1, December 31, 1949) describes an attractive exhibit which has been prepared in the Museum. In view of the increasing interest in the collecting of stamps according to the subjects or scenes shown thereon, the Museum has installed a display of 192 sheets showing mammals, birds, fishes and other animals. The display was presented by Mr. J. Whitsed Dovey, of Roseville, Sydney, and covers a representative selection of his collection of fifteen thousand zoological stamps. About 250 different zoological subjects have appeared on the postage stamps of all countries, and the modern tendency to add variety to stamp designs by depicting some of the fauna of the country concerned is illustrated by the current Australian stamps showing a kangaroo, an emu, a kookaburra, a platypus, a lyre bird and a crocodile, besides a merino ram and a Hereford bull, representative of Australian pastoral and grazing industries. Previous Australian issues have featured other subjects, such as a swan, a horse and a dove. In all these cases the zoological subject has been the main feature of the design. The display in the Museum was made up of two thousand stamps and was accompanied by scientific descriptions prepared by members of the Museum staff.

\section{Taxonomy of Tropical African Plants}

A Meeting, attended by twenty-one botanists interested in the flora of tropical Africa and representing six different institutrons, was held in the Herbarium of the Royal Botanic Gardens, Kew, on September 15, with Dr. W. B. Turrill, keeper of the Herbarium and Library, in the chair. It was unanimously decided to form an association of botanists interested in the taxonomy of tropical African plants, with the view of increasing international collaboration among such botanists, and of correlating the taxonomy and nomenclature in regional floras (Angola, Belgian Congo, Tropical East Africa, etc.) now in preparation. Dr. J. Leonard, of l'Institut National pour l'Étude Agronomique du Congo Belge, 236 Rue Royale, Brussels, was elected secretary. A fuller account of the meeting, and of the aims of the new association, will be published in the Bulletin de la Sociéte Royale de Botanique de Belgique early next year. Meanwhile any information regarding the association can be obtained from the secretary.

\section{Focus : A Geographical Study of Modern Events}

A FovR-Page leaflet entitled Focus is published by the American Geographical Society ( 1 dollar per ten issues). It is to appear monthly except in July and August. Focus aims at providing a geographical background to the major events in the world. Physical features, land use, communications, mineral and power resources play an important part in political events and are too often overlooked. The first number deals entirely with Korea and gives a brief summary of the country's features and resources, with special insistence on the country's unity and the unsuitability of the parallel of $38^{\circ} \mathrm{N}$. as a political barrier. A number of maps show that the products of North and South Korea are complementary. The North needs rice and barley from the South and produces coal, iron and power; but the bulk of the population lies in the South and that, too, is the part with the most extensive plains. From time to time map supplements will be issued with Focus. The first of these is a map of the world on a scale of $1: 30,000,000$. Future subjects will be the oil resources of the U.S.S.R., water problems in the United States and the strategic position of Iran.

\section{Bulletin of the Raffles Museum}

THE Second World War and subsequent banditry have caused a long interruption in anthropological work in Malaya, and the disturbance to aboriginal life which they have brought about has rendered it more urgent if much information is not to be lost for ever. The appearance of the Bulletin of the Raffles Museum (Series B, No. 4, December 1949 ; Singapore : Malayan Government; $4 s$. $8 d$.), the first since the War, is therefore most timely. It includes an article on air photography by P. D. R. Williams-Hunt, an aboriginal word-list and a number of notes and short articles by $\mathrm{H}$. D. Collings, and a contribution by H. D. Noone, whose death during the Japanese occupation was a grievous loss to anthropology. It is to be hoped that circumstances will now allow the Bulletin to appear regularly.

\section{A Study of Drying}

THE Institute of Fuel has decided to make "A Study of Drying" during the 1950-51 session, and for this purpose a committee of thirteen, with $T$. C. Bailey as chairman, has recently been formed. The aims of the Study are threefold: the fundamental principles of the drying of materials and the main features of drying practice, with emphessis on overall thermal efficiency; new methods and techniques; assessment of the limitations of existing knowledge and consideration of new fields to explore. The removal of water by filtration, pressing, centrifuging, crystallization or sedimentation falls outside the scope of this investigation. The Study will consist of the presentation of a number of papers, followed by discussion, and the first three papers will be given on December 5 at 5.30 p.m. at the Institution of Mechanical Engineers, Storey's Gate, St. James's Park, London, S.W.1 (admission free). The subjects and speakers are: "Some Fundamental Aspects of AirDrying of Solids", by R. Hendry and Dr. A. W. Scott ; "The Determination of Moisture in Coal", by E. G. Barber ; and "Methods of Estimating Moisture", by A. H. Ward. Further papers will be given later in various regions of Great Britain, and the Study will conclude with a conference in London. The whole programme has been arranged under the following headings : fundamentals of drying ; drying in the textile, paper and allied industries; drying in the clay industry; drying of pastes, powders and crystals; drying of fuels, sand, etc. ; drying in agriculture and forestry; and drying of animal by. products and miscellaneous substances. Members of 